\title{
The rs2228145 polymorphism in the interleukin-6 receptor and its association with long-term prognosis after myocardial infarction in a pilot study
}

Anna Szpakowicz ${ }^{1}$, Witold Pepinski², Ewa Waszkiewicz'1 Małgorzata Skawronska², Anna Niemcunowicz-Janica ${ }^{2}$, Wlodzimierz J. Musial ${ }^{1}$, Karol A. Kaminski ${ }^{1}$

${ }^{1}$ Department of Cardiology, Medical University of Bialystok, Bialystok, Poland ${ }^{2}$ Department of Forensic Medicine, Medical University of Bialystok, Bialystok, Poland

Submitted: 8 April 2015

Accepted: 1 June 2015

Arch Med Sci 2017; 13, 1: 93-99

DOI: $10.5114 /$ aoms.2016.58636

Copyright $\odot 2016$ Termedia \& Banach

\section{Abstract}

Introduction: Interleukin-6 (IL-6) is a cytokine with a complex function that is described as both pro- and anti-inflammatory. One factor that influences its function is the rs2228145 A/C single nucleotide polymorphism (SNP) of the IL-6 receptor (IL6R) gene. C allele carriers have a decreased inflammatory response and decreased prevalence of ischemic heart disease. The aim of the study was to investigate the association of the rs2228145 SNP of the IL6R gene with long-term total mortality in patients with ST-elevation myocardial infarction (STEMI) treated invasively.

Material and methods: We analyzed the data of consecutive patients with ST elevation myocardial infarction (STEMI) treated with primary percutaneous coronary intervention ( $\mathrm{PCl}$ ). Genotyping was performed with the TaqMan method. The analyzed end-point was total long-term mortality (median: 2875 days). Results: The registry comprised 553 patients (mean age: $62.4 \pm 11.9$ years; $25.6 \%$ females, $n=142$; TIMI 3 obtained in $91.7 \%$ of patients, $n=507$ ). No significant differences in baseline characteristics were found between the genotypes. During long-term follow-up 171 (30.9\%) patients died. There was non-significantly higher mortality in the rs2228145 AA homozygotes compared to $\mathrm{C}$ allele carriers $(\mathrm{OR}=1.34,95 \% \mathrm{Cl}: 0.93-1.93, p=0.1)$.

Conclusions: The rs2228145 polymorphism of IL6R was not significantly associated with long-term mortality after STEMI. However, AA homozygotes (high-risk genotype for ischemic heart disease) showed a trend towards adverse outcome compared to $\mathrm{C}$ allele carriers. The observed trend is promising, but it requires independent replication studies.

Key words: interleukin-6, IL-6 receptor, ST elevation myocardial infarction, acute coronary syndrome.

\section{Introduction}

Interleukin-6 (IL-6) is a cytokine with a very complex function that is described as both pro- and anti-inflammatory. Therefore, it is not resolved yet whether it is a causative factor for atherosclerosis and heart failure, just a risk marker, or even a compensatory agent (like B-type natriuretic peptide in heart failure). An increased concentration of IL-6 is associated with higher prevalence of acute coronary syndrome [1, 2], adverse subsequent prognosis in this group of patients [3-5], and increased risk for development of heart failure $[6,7]$. Interleukin- 6 is se-
Corresponding author: Karol A. Kaminski MD, PhD Department of Cardiology Medical University of Bialystok

24a M. Skłodowskiej-Curie St 15-276 Bialystok, Poland Phone: +48 857468656 Fax: +48 857468604 E-mail: fizklin@wp.pl 
creted by myocardium during acute myocardial infarction and following reperfusion [8].

The multidirectional influence of IL-6 on the cardiovascular system can be explained by its very complex interaction with receptors: the IL-6 receptor (IL6R, glycoprotein 80, CD126) and glycoprotein 130 (gp130, IL6ST - IL-6 signal transducer, CD130). Both of them can exist in a soluble form (sIL6R and sgp130) or as membrane bound receptors. A specific IL- 6 binding subunit, IL-6R, is present only on a few cell types (hepatocytes, leukocytes), whereas the subunit common for all IL- 6 family cytokines, gp130 (necessary to activate intracellular transduction cascades), is expressed on all types of cells. The signaling pathways of IL- 6 are different depending on the primary form of IL- 6 (free or bound to soluble receptors), adequate effector membrane receptors, and stimulated cell lines.

Another factor that influences IL-6 function is the rs2228145 A/C single nucleotide polymorphism (SNP) in the intron of an IL6R gene. The $C$ allele is associated with increased sIL6R concentrations [9-11], decreased IL6R membrane expression on monocytes and CD4+ lymphocytes, and decreased response to IL-6 (decreased phosphorylation of STAT1 and STAT3) [10]. This phenomenon can potentially be explained by the mechanism of increased cleavage of the membrane receptor to plasma [12]. $\mathrm{C}$ allele carriers have a decreased inflammatory response as well as decreased prevalence of atrial fibrillation, diabetes, metabolic syndrome, aortic aneurysm and rheumatoid arthritis [10, 13-15]. In patients with aortic stenosis the $C$ allele was associated with lower transvalvular gradients [16]. A recent meta-analysis of 82 studies confirmed that the rs2228145 SNP is also associated with all forms of coronary heart disease (CHD) in patients of European descent [9]. This finding was not confirmed in Han Chinese with premature CHD (age $<55$ years in men or $<65$ years in women) [17]. In this analysis the SNP also failed to associate with severity of atherosclerotic lesions or clinical phenotypes of CHD [17]. The study, however, was limited by the small number of patients included ( $n=187$ cases).

The association between the rs2228145 polymorphism and CHD in the European population has already been reliably confirmed. Still, there are no studies focusing on long-term prognosis after myocardial infarction, which is a specific form of CHD. Therefore, the aim of the study was to investigate the association of the rs2228145 SNP of the IL6R gene with 5-year total mortality in patients with ST-elevation myocardial infarction (STEMI) treated invasively.

\section{Material and methods}

This was a retrospective observational study performed in a real-life registry of patients with STEMI.
As described previously [18-20], the registry included consecutive patients with STEMI admitted to our department in the years 2001-2005 and treated invasively within $12 \mathrm{~h}$ from symptoms onset. On the day of admission, after obtaining informed written consent, blood samples were collected. Afterwards, clinical data were retrieved retrospectively from hospital documentation. In this way we constructed a real-world registry, with no exclusion criteria except for lack of consent. In this analysis, however, we focused on long-term outcome and therefore selected only those individuals who survived the first $48 \mathrm{~h}$ after hospital admission.

ST-elevation myocardial infarction was diagnosed based on a history of typical chest pain, ECG changes (ST-segment elevation or a new left bundle branch block) and a rise in cardiac necrosis markers. Pharmacological treatment was consistent with contemporary guidelines. The database comprised patients' history, data from physical examination on admission, laboratory tests, echocardiography, and coronary angiography. The GRACE risk score was calculated retrospectively, based on data collected on admission [21].

The control group comprised 51 adult men and 50 adult women, who took part in paternity testing. Detailed clinical characteristics were not available, but such a random group should be highly representative in terms of the genetic background for our region.

Blood samples for genotype testing were collected in EDTA tubes and stored at $-20^{\circ} \mathrm{C}$. Commercial kits were used for DNA extraction (Blood Mini, A\&A Biotechnology). Genotypes were determined with TaqMan SNP Genotyping Assay on the ABI 7500 real-time PCR platform (Applied Biosystems). Ten percent of the samples were genotyped in duplicate.

Long-term follow-up was performed (maximum: 4167, minimum: 2558 days). The analyzed end-point was all-cause mortality. Survival status was retrieved from the local population registry run by a Government Office.

The research was performed in accordance with the ethical standards laid down in the 1964 Declaration of Helsinki. Informed written consent was obtained from all the subjects before their inclusion in the study. The protocol was approved by the Ethics Review Board of the Medical University of Bialystok.

\section{Statistical analysis}

Statistical analysis was performed with Statistica 9.0 and ARLEQUIN v.3.0 (Hardy-Weinberg equilibrium) software. The 3 genotypes of the rs2228145 SNP were compared in terms of clinical parameters ( $\chi^{2}$ or Kruskal-Wallis ANOVA test, as appropriate) and mortality rates ( $\chi^{2}$ test). Based on visual analy- 
sis of Kaplan-Meier survival curves, patients with CC and AC genotypes were combined into one group for additional analysis. Probability of survival was compared with the log-rank test. For univariate and multivariate analyses, logistic regression was used. Variables from univariate analysis significantly associated with mortality (except for the GRACE risk score) were entered into a primary model of multivariate analysis and further eliminated in a backward stepwise manner. A two-sided $p$ value $<0.05$ was considered statistically significant.

\section{Results}

We enrolled in the registry 652 subjects, 9 of whom were lost to follow-up (1.4\%). Genotyping was successfully performed in 553 patients, which constituted our study group. No discrepancies were observed in the results of samples genotyped in duplicate. The control group comprised 101 subjects who underwent paternity testing.

The percentages of specific genotypes of the rs2228145 SNP and both study and control groups are shown in Table I.
Table I. Percentages of specific genotypes of the rs2228145 polymorphism and associated mortality rates

\begin{tabular}{|c|c|c|c|}
\hline Genotype & AA & $A C$ & $\mathrm{CC}$ \\
\hline \multicolumn{4}{|c|}{ Study group $(n=553)$ : } \\
\hline Number (\%) & $243(43.9)$ & $242(43.8)$ & $68(12.3)$ \\
\hline $\begin{array}{l}\text { Long-term } \\
\text { mortality, } n \text { (\%) }\end{array}$ & $34.6(84)^{\star}$ & $28.5(69)$ & $26.5(18)$ \\
\hline \multicolumn{4}{|c|}{ Control group $(n=101)$ : } \\
\hline Number (\%) & $35(34.65)$ & $51(50.5)$ & $15(14.85)$ \\
\hline
\end{tabular}

There was a trend towards higher prevalence of the $C$ allele (protective one) in the control group, $p=0.21, \chi^{2}$ test. Both groups were in Hardy-Weinberg equilibrium ( $p$-values 0.52 and 0.6 , consecutively). Mean age in the study group was $62.4 \pm 11.9$ years, $25.6 \%$ of the group were female $(n=142)$, and TIMI 3 after PCl was obtained in $91.7 \%$ of patients $(n=507)$. Detailed clinical characteristics of the study group are presented in Table II. No sig-

Table II. Baseline characteristics of the study group based on rs2228145 genotype (risk allele for myocardial infarction - A)

\begin{tabular}{|c|c|c|c|c|c|}
\hline Characteristic & $\begin{array}{c}\text { Overall } \\
\text { population } \\
N=553\end{array}$ & $\begin{array}{c}\text { rs } 2228145 \\
\text { AA homozygotes } \\
N=243\end{array}$ & $\begin{array}{c}\text { rs2228145 } \\
\text { AC heterozygotes } \\
N=242\end{array}$ & $\begin{array}{c}\text { rs } 2228145 \\
\text { CC homozygotes } \\
N=68\end{array}$ & $P$-value \\
\hline Age [years] & $62.4(11.9)$ & $63.1(11.7)$ & $61.8(12.6)$ & $62.4(10.0)$ & 0.44 \\
\hline Female gender (\%) & $25.6(n=142)$ & $25.1(n=61)$ & $24.0(n=58)$ & $33.8(n=23)$ & 0.24 \\
\hline Hypertension (\%) & $55.1(n=305)$ & $56.4(n=137)$ & $52.9(n=128)$ & $58.8(n=40)$ & 0.60 \\
\hline Type 2 diabetes (\%) & $22(n=122)$ & $23.9(n=58)$ & $22.3(n=54)$ & $14.7(n=10)$ & 0.27 \\
\hline $\begin{array}{l}\text { Previous myocardial } \\
\text { infarction (\%) }\end{array}$ & $10.1(n=56)$ & $9.0(n=22)$ & $11.6(n=28)$ & $8.8(n=6)$ & 0.61 \\
\hline $\begin{array}{l}\text { Systolic blood pressure } \\
{[\mathrm{mm} \mathrm{Hg}]}\end{array}$ & $138.5(28.7)$ & $139.6(27.9)$ & $137.6(28.9)$ & $138.1(30.9)$ & 0.45 \\
\hline Heart rate [beats/min] & $75.5(17.8)$ & $76.7(18.9)$ & $75.4(17.3)$ & $72.1(14.6)$ & 0.17 \\
\hline Killip class III or IV (\%) & $6.5(n=36)$ & $7.8(n=19)$ & $6.6(n=16)$ & $1.5(n=1)$ & 0.17 \\
\hline $\begin{array}{l}\text { ST-elevation in anterior } \\
\text { leads (\%) }\end{array}$ & $39.0(n=216)$ & $42.4(n=103)$ & $36.8(n=89)$ & $35.3(n=24)$ & 0.39 \\
\hline $\begin{array}{l}\text { TIMI flow grade } 3 \text { after } \\
\text { procedure (\%) }\end{array}$ & $91.7(n=507)$ & $93.4(n=227)$ & $90.5(n=219)$ & $89.7(n=61)$ & 0.41 \\
\hline Stent implantation (\%) & $76.8(n=425)$ & $76.5(n=186)$ & $78.9(n=191)$ & $70.6(n=48)$ & 0.35 \\
\hline $\begin{array}{l}\text { No. of vessels with } \\
\text { significant stenosis }\end{array}$ & $1.71(0.8)$ & $1.72(0.82)$ & $1.71(0.79)$ & $1.69(0.79)$ & 0.93 \\
\hline Creatinine $[\mathrm{mg} / \mathrm{dl}]$ & $1.036(0.41)$ & $1.06(0.48)$ & $1.0(0.34)$ & $1.03(0.32)$ & 0.12 \\
\hline Total cholesterol [mg/dl] & $195.8(42.3)$ & $191.7(45.6)$ & $198.8(40.2)$ & $199.8(36.2)$ & 0.06 \\
\hline LDL cholesterol [mg/dl] & $128.4(37.8)$ & $124.9(40.6)$ & $131.2(36.2)$ & $131.1(32.4)$ & 0.09 \\
\hline HDL cholesterol [mg/dl] & $43.8(13.2)$ & $44.0(14.6)$ & $43.6(11.9)$ & $43.7(12.1)$ & 0.85 \\
\hline Triglycerides [mg/dl] & $123.0(66.3)$ & $120.7(64.5)$ & $122.3(61.0)$ & $133.7(88.0)$ & 0.77 \\
\hline Hemoglobin [g/dl] & $13.5(7.0)$ & $13.5(6.7)$ & $13.6(8.2)$ & $13.1(1.7)$ & 0.88 \\
\hline Ejection fraction (\%) & $46.0(9.5)$ & $45.3(9.6)$ & $46.6(9.7)$ & $46.5(8.8)$ & 0.19 \\
\hline GRACE risk score & $149.8(34.8)$ & $151.9(33.7)$ & $148.8(35.5)$ & $146(28.0)$ & 0.23 \\
\hline
\end{tabular}




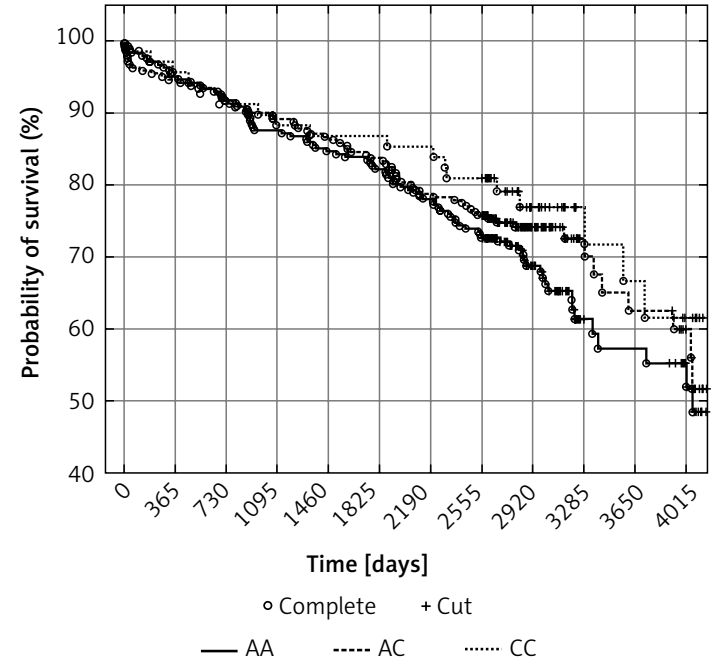

Figure 1. Kaplan-Meier survival curves for the rs2228145 genotypes and long-term observation. $P=0.38$ (analysis of 3 genotypes); $p=0.14$ (AA homozygotes and $\mathrm{C}$ allele carriers), log-rank test

nificant clinical differences were found between the genotypes.

A long-term follow-up was performed (median of censored observations 2875 days, maximum 4167, minimum 2558). During observation 171 (30.9\%) patients died. Mortality rates for the rs2228145 genotypes are presented in Table I. There was a trend for lower mortality in C allele carriers compared to AA homozygotes $(28.1 \%$ vs. $34.6 \%, p=0.1, \chi^{2}$ test). Figure 1 shows $\mathrm{Ka}$ plan-Meier survival curves for the rs2228145 genotypes and long-term observation.

The trend towards adverse outcome in AA homozygotes compared to $C$ allele carriers was not statistically significant ( $p=0.14$, log-rank test). In univariate analysis (logistic regression, Table III) the rs2228145 AA genotype was not significantly associated with long-term outcome (OR $=1.34$ 95\% Cl: 0.93-1.93, $p=0.1$ ). In multivariate analysis the variables independently associated with long-term outcome were age, Killip class on admission, and ejection fraction (Table III).

\section{Discussion}

We did not prove an association between the rs2228145 polymorphism and long-term mortality after STEMI. However, AA homozygotes showed a trend towards adverse outcome compared to $C$ allele carriers. In the early phase of follow-up, Kaplan-Meier survival curves overlapped, and they started to diverge in the third year of observation. This confirms that the reported effect was independent of potential differences in the acute

Table III. Univariate and multivariate analysis for long-term mortality

\begin{tabular}{|c|c|c|c|}
\hline Variable & Hazard ratio & $95 \% \mathrm{Cl}$ & $P$-value \\
\hline \multicolumn{4}{|l|}{ Univariate analysis: } \\
\hline Age [years] & 1.07 & $1.05-1.088$ & $<0.0001$ \\
\hline Heart rate [beats/min] & 1.012 & $1.002-1.022$ & 0.018 \\
\hline Systolic blood pressure [mm Hg] & 0.92 & $1.0003-0.99$ & 0.91 \\
\hline Killip class & 2.07 & $1.6-2.65$ & $<0.0001$ \\
\hline Type 2 diabetes & 1.9 & $1.2-2.8$ & 0.003 \\
\hline Previous myocardial infarction & 2.0 & $1.1-3.5$ & 0.017 \\
\hline Anterior myocardial infarction & 1.3 & $0.91-1.89$ & 0.14 \\
\hline TIMI 3 flow after $\mathrm{PCI}$ & 0.52 & $0.28-0.94$ & 0.03 \\
\hline No. of vessels with significant stenosis & 1.18 & $0.94-1.47$ & 0.14 \\
\hline Ejection fraction (\%) & 0.95 & $0.93-0.96$ & $<0.0001$ \\
\hline Creatinine $[\mathrm{mg} / \mathrm{dl}]$ & 2.2 & $1.3-3.7$ & 0.003 \\
\hline GRACE risk score & 1.021 & $1.015-1.027$ & $<0.0001$ \\
\hline rs2228124 AA genotype & 1.34 & $0.93-1.93$ & 0.1 \\
\hline \multicolumn{4}{|l|}{ Multivariate analysis: } \\
\hline Age [years] & 1.06 & $1.04-1.08$ & $<0.0001$ \\
\hline Killip class & 1.67 & $1.26-2.2$ & 0.0002 \\
\hline Ejection fraction (\%) & 0.97 & $0.94-0.99$ & 0.004 \\
\hline
\end{tabular}


phase of myocardial infarction. Our findings are consistent with previous papers defining adenosine as a risk allele for ischemic heart disease and cytosine as a protective one [9].

In a recent study performed in patients with inflammatory polyarthritis (the Norfolk Arthritis Register) the rs2228145 polymorphism was associated neither with all-cause nor with cardiovascular mortality [22]. The investigated cohort, however, cannot be directly compared to our homogenous group of patients with STEMI, who are at notably high risk of death. Inflammatory polyarthritis is a disorder of a very heterogeneous etiology. It includes various forms of systemic rheumatic illnesses (e.g. rheumatoid arthritis, lupus), inflammatory osteoarthritis, infectious and postinfectious arthritis, seronegative spondyloarthritides, and other systemic disorders (e.g. sarcoidosis, malignancies). All those illnesses affect multiple organs and also increase the risk of cardiovascular death, but not as specifically as a history of myocardial infarction (only $54 \%$ of deaths in the Norfolk Arthritis Register were reported as cardiovascular). The next important difference is the large dispersion in time of observation: in the Norfolk Arthritis Register, patients were enrolled in the years 1990-2011. During that long time, $23 \%$ of them died, which is comparable to the 5 -year mortality of patients with STEMI [23]. Finally, patients from that study were not clinically verified for previous cardiovascular disease, and cardiovascular deaths were defined solely based on death certificates, which may be unreliable.

The $C$ allele carriers have increased sIL6R concentrations [9-11], decreased IL6R membrane expression, and decreased response to IL-6 [10]. Under normal conditions, a majority of the IL- 6 in the plasma forms a complex with sIL6R. The sIL6R-IL-6 complex binds membrane gp130, which is available on most cell types in the body and is responsible for further signal transduction. This phenomenon is called IL-6 trans-signaling. Alternatively, the complex can be bound by a soluble form of gp130 that acts as a trans-signaling inhibitor. The free form of IL-6, which is in minority, binds membrane IL6R that acts further via membrane gp130. The membrane IL6R is present only on selected cell types: hepatocytes, macrophages/monocytes, neutrophils, and some subpopulations of lymphocytes. Its availability on cardiomyocytes has been discussed. To sum up, an IL-6 complex with sIL6R interacts with a majority of cells in the body (if not inhibited by sgp130) and free IL-6 can stimulate only specific cells with membrane IL6R. In $C$ allele carriers, the balance between the soluble and membrane form of IL6R is shifted, probably due to increased cleavage of the membrane receptor to plasma [12] and further change in the effector cells. This results in a phenotype of decreased prevalence of cardiovascular disease, including ischemic heart disease [9]. Such an effect after myocardial infarction can potentially extend to a decreased number of subsequent cardiovascular events and mortality.

The function of IL-6 is very complex: both proand anti-inflammatory effects are described. Classically, IL- 6 increases production of acute phase proteins in liver and expression of adhesive molecules in endothelium. These mechanisms promote atherosclerosis. On the other hand, IL- 6 enhances production of the IL-10 and IL-1 receptor antagonist and has a cytoprotective effect for cardiomyocytes [24]. An increase in local expression of IL-6 has been observed in ischemia-reperfusion models, experimental $[25,26]$ as well as clinical $[27,28]$. Previous studies in our material supported the hypothesis that during scheduled percutaneous coronary interventions an increase in IL- 6 plasma concentration has a global rather than a local character, as there were no significant gradients between the aorta and coronary sinus [29]. All the reports make interpretation of the role of IL6R and its associated SNP more complex and difficult; however, there is a general opinion that the effects of IL-6 trans-signaling are predominantly pro-inflammatory [30].

Despite all the advances in treatment of acute myocardial infarction, long-term prognosis in this group of patients remains poor. Therefore, every effort is being made to improve not only therapy but also risk stratification. Novel parameters helpful in the assessment of prognosis are continuously searched for [31-33]. High-risk patients require more intensive ambulatory monitoring and more aggressive treatment. Basic clinical parameters will always have the greatest value in this field. However, due to decreasing costs and increasing availability, genetic tests are still a promising option that could supplement the traditional approach.

Several limitations of the study need to be acknowledged. First, the number of patients enrolled in the research was not sufficient to prove a significant correlation between the genotype and survival. Further research is required in this field. Next, the effect of the genotype was revealed after a very long-term follow-up. In our case, the mean time of observation was almost 8 years, and the first effect started in the $3^{\text {rd }}$ year of observation. The longer the observation, the less specific the effect - in the case of this analysis, the less specific for cardiac mortality. Moreover, we had no possibility to analyze plasma samples for IL-6, IL6R, or CRP concentrations, which would have improved the quality of the study. Finally, the research was performed retrospectively (although the data were collected in a prospective manner). 
In conclusion, The rs2228145 polymorphism of the IL6R was not significantly associated with longterm mortality after STEMI. However, AA homozygotes (a high-risk genotype for ischemic heart disease) showed a trend towards an adverse outcome compared to $C$ allele carriers. Further research in this field is required, because the observed effect size is promising for clinical utilization.

\section{Acknowledgments}

The project was supported by a grant from the Medical University of Bialystok No. N/ST/MN/ 15/002/1153.

\section{Conflict of interest}

The authors declare no conflict of interest.

\section{References}

1. Ridker PM, Rifai N, Stampfer MJ, Hennekens CH. Plasma concentration of interleukin- 6 and the risk of future myocardial infarction among apparently healthy men. Circulation 2000; 101: 1767-72.

2. Yamashita H, Shimada K, Seki E, Makuno H, Daida H. Concentration of interleukins, interferon and C-reactive protein in stableand unstable angina pectori. Am J Cardiol 2003; 91: 133-6.

3. Biasucci LM, Liuzzo G, Fantuzzi G, et al. Increasing levels of interleukin (IL)-1Ra and IL-6 during first 2 days of hospitalization in unstable angina are associated with increased risk of in-hospital coronary events. Circulation 1999; 99: 2079-84.

4. Lindmark E, Diderholm E, Wallentin L, Siegbahn A. Relationship between interleukin 6 and moratlity in patients with unstable coronary artery disease: effects of an early invasive or noninvasive strategy. JAMA 2001; 286: 2107-13.

5. Hojo Y, Ikeda U, Katsuki T, et al. Interleukin-6 expression in coronary circulation after coronary angioplasty as risk factor for restenosis. Heart 2000; 84: 83-7.

6. Torre-Amione G, Kapadia S, Benedict C, Oral H, Young JB, Mann DL. Proinflammatory cytokine levels in patients with depressed left ventricular ejection fraction: a report from the Studies of Left Ventricular Dysfunction (SOLVD). J Am Coll Cardiol 1996; 27: 1201-6.

7. Vasan RS, Sullivan LM, Roubenoff R, et al. Inflammatory markers and risk of heart failure in elderly subjects without prior myocardial infarction: the Framingham Heart Study. Circulation 2003; 107: 1486-91.

8. Kaminski KA, Kozuch M, Bonda T, et al. Coronary sinus concentrations of interleukin 6 and its soluble receptors are affected by reperfusion and may portend complications in patients with myocardial infarction. Atherosclerosis 2009; 206: 581-7.

9. IL6R Genetics Consortium Emerging Risk Factors Collaboration. Interleukin-6 receptor pathways in coronary heart disease: a collaborative meta-analysis of 82 studies. Lancet 2012; 379: 1205-13.

10. Ferreira RC, Freitag DF, Cutler AJ, et al. Functional IL6R 358Ala allele impairs classical IL-6 receptor signaling and influences risk of diverse inflammatory diseases. Plos Genet 2013; 9: e1003444.

11. Revez JA, Bain L, Chapman B, et al. A new regulatory variant in the interleukin- 6 receptor gene associates with asthma risk. Genes Immun 2013; 14: 441-6.
12. Hawkins GA, Robinson MB, Hastie AT, et al. The IL6R variation Asp(358)Ala is a potential modifier of lung function in subjects with asthma. J Allergy Clin Immunol 2012; 130: 510-5.

13. Harrison SC, Smith AJ, Jones GT, et al. Interleukin-6 receptor pathways in abdominal aortic aneurysm. Eur Heart J 2013; 34: 3707-16.

14. Hamid YH, Urhammer SA, Jensen DP, et al. Variation in the interleukin-6 receptor gene associates with type 2 diabetes in Danish whites. Diabetes 2004; 53: 3342-5.

15. Esteve E, Villuendas G, Mallolas J, et al. Polymorphisms in the interleukin-6 receptor gene are associated with body mass index and with characteristics of the metabolic syndrome. Clin Endocrinol (Oxf) 2006; 65: 88-91.

16. Wypasek E, Potaczek DP, Lamplmayr M, Sadowski J, Undas A. Interleukin-6 receptor Asp358Ala gene polymorphism is associated with plasma C-reactive protein levels and severity of aortic valve stenosis. Clin Chem Lab Med 2014; 52: 1049-56.

17. Chen Z, Qian Q, Tang C, et al. Association of two variants in the interleukin-6 receptor gene and premature coronary heart disease in a Chinese Han population. Mol Biol Rep 2013; 40: 1021-6.

18. Szpakowicz A, Pepinski W, Waszkiewicz E, et al. The influence of renal function on the association of rs 854560 polymorphisms of paraoxonase 1 gene with long-term prognosis in patients after myocardial infarction. Heart Vessles 2016; 31: 15-22.

19. Szpakowicz A, Kiliszek M, Pepinski W, et al. Polymorphism of 9p21.3 locus is associated with 5-year survival in high-risk patients with myocardial infarction. PLoS One 2014; 9: e104635.

20. Szpakowicz A, Kiliszek M, Pepinski W, et al. The rs9982601 polymorphism of the region between the SLC5A3/MRPS6 and KCNE2 genes associated with a prevalence of myocardial infarction and subsequent long-term mortality. Pol Arch Med Wewn 2015; 125 : 240-8.

21. Granger CB, Goldberg RJ, Dabbous O, et al. Global Registry of Acute Coronary Events Investigators. Predictors of hospital mortality in the Global Registry of Acute Coronary Events. Arch Intern Med 2003; 163: 2345-53.

22. Ibrahim I, McAllister K, Plant D, et al. Investigation of an interleukin-6 receptor gene polymorphism (rs2228145) as a predictor of cardiovascular mortality in inflammatory polyarthritis: results from the Norfolk Arthritis Register. Ann Rheum Dis 2014; 73: 787-8.

23. Kozieradzka A, Kamiński KA, Maciorkowska D, et al. GRACE, TIMI, Zwolle and CADILLAC risk scores: do they predict 5-year outcomes after ST-elevation myocardial infarction treated invasively? Int J Cardiol 2011; 148: 70-5.

24. Wollert KC, Drexler H. The role of interleukin- 6 in the failing heart. Heart Fail Rev 2001; 6: 95-103.

25. Kukielka GL, Smith CW, Manning AM, et al. Induction of interleukin 6 in the myocardium. Possible role in postreperfusion inflammatory injury. Circulation 1995; 92: 1866-75.

26. Deten A, Volz HC, Briest W, Zimmer HG. Cardiac cytokine expression is upregulated in the acute phase after myocardial infarction. Experimental studies in rats. Cardiovasc Res 2002; 55: 329-40.

27. Zahler S, Massoudy P, Harl H, Haehnel C, Meisner H, Becker BF. Acute cardiac inflammatory responses to postischemic reperfusion during cardiopulmonary bypass. Cardiovasc Res 1991; 41: 722-30. 
28. Neumann FJ, Ott I, Gawaz M, et al. Cardiac release of cytokines and inflammatory responses in acute myocardial infarction. Circulation 1995; 92: 748-55.

29. Kamiński KA, Kozieradzka A, Bonda T, et al. Percutaneous coronary interventions affect concentrations of interleukin 6 and its soluble receptors in coronary sinus blood in patients with stable angina. Angiology 2009; 60: 322-8.

30. Waetzig GH, Rose-John S. Hitting a complex target: an update on interleukin-6 transsignalling. Expert Opin Ther Targets 2012; 16: 225-36.

31. Jeżewski T, Peruga JZ, Kasprzak JD, et al. In-hospital daily insulin dose predicts long-term adverse outcome in patients with diabetes with ST-elevation myocardial infarction treated with successful primary percutaneous angioplasty. Arch Med Sci 2014; 10: 913-9.

32. Komócsi A, Aradi D, Kehl D, et al. Meta-analysis of randomized trials on access site selection for percutaneous coronary intervention in ST-segment elevation myocardial infarction. Arch Med Sci 2014; 10: 203-12.

33. Wu G, Sun G, Zhao R, Sun M. Clinical outcomes of second- versus first-generation drug-eluting stents in patients with acute myocardial infarction: a meta-analysis of randomized controlled trials. Arch Med Sci 2014; 10 643-50. 